\title{
Development and testing of flexible core-tube in lunar subsurface sampler
}

\author{
TANG Dewei $^{1, \text { a }}$, GAO Xingwen ${ }^{1, b}$ YUE Honghao ${ }^{1, c}$ and LI Yanwei ${ }^{1}$ \\ ${ }^{1}$ Harbin Institute of Technology, Harbin, China \\ adwtang@hit.edu.cn, bgaoxing_hit@163.com, ’block@hit.edu.cn
}

Keywords: PBO, lunar subsurface sampler, flexible core-tube

Abstract. In the field of lunar subsurface drilling and sampling, flexible core-tube sampler has the advantages that it can maintain the layered information and mechanism of the lunar soil sample. In this paper the PBO fiber is proposed as the textile material of the core-tube, along with its proceeding technology. The mechanical properties of this new type of flexible core-tube is verified in vacuum, low temperature $\left(-180^{\circ} \mathrm{C}\right)$ and high temperature $\left(120^{\circ} \mathrm{C}\right)$ environment.

\section{Introduction}

Recently, lunar exploration has received lots of attention. Subsurface investigation technologies have achieved great development in order to meet the needs of investigating the geological composition, properties and the change of lunar subsurface profile with the buried depth, etc. In the 1960s, American astronauts gathered the samples with geological hammer, core tube, scoop, tongs, etc. [1]. And in the 1970s, the Luna 24 launched by the former Soviet union successfully collected $2.5 \mathrm{~m}$ depth of drill core sample from Mare Crisium and returned it to Earth automatically, the samples were obtained with a rotary dill [2]. The Chinese lunar investigation project adopts unmanned Luna subsurface sampler to gather lunar soil and return it to Earth. The operating principle of sampler is shown in Fig. 1. The sample that flowed through the drilling bit is obtained with a flexible core-tube which is inside the auger. All the other parts of the sampler are abandoned expect the flexible core-tube which is extracted by a drawstring after the drilling process complete.

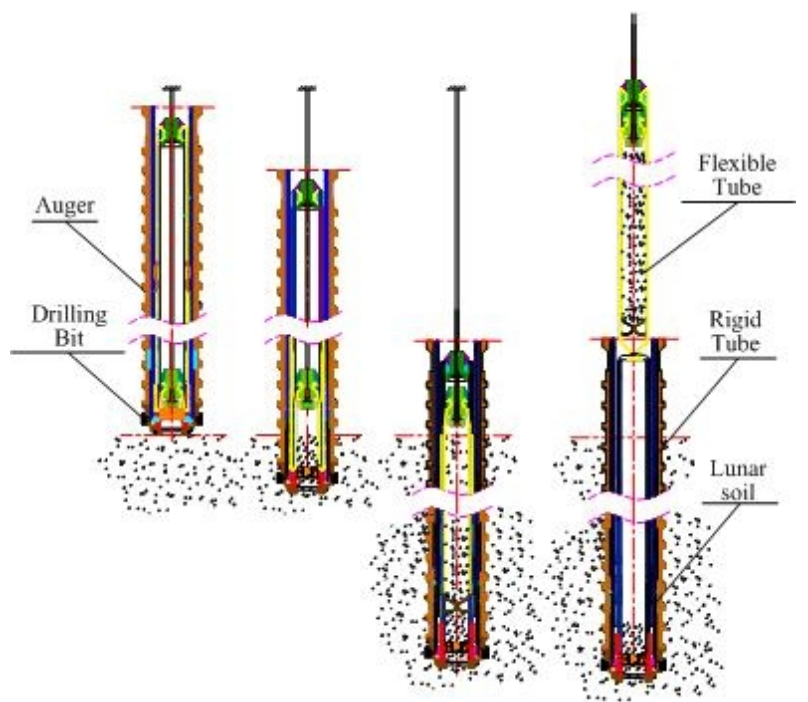

Fig. 1 The operating principle of the flexible core-tube sampler

Flexible core-tube is a crucial part in the sampler. It is directly in contact with the sample, protects the original bedding architecture and physical properties of the sample. However, the lunar environment restricts the application of the flexible core-tube. The most obvious environmental factors that concern people are extreme temperature fluctuations, and the virtual absence of any atmosphere [3]. The surface temperature can vary from $-233^{\circ} \mathrm{C}$ at night in the polar regions to $+123^{\circ} \mathrm{C}$ during the day in the equatorial regions, the high temperature gradient needs to be addressed to make sure the flexible core-tube can survive this potentially damaging condition [4]. Meanwhile, because of the 
absence of atmosphere, it is difficult to remove the cutting heat from the drilling bit. The flexible core-tube near the bit will be in a high temperature environment. To avoid the disturbing of original bedding architecture and physical properties, the longitudinal stiffness of the flexible core-tube should be strong enough in order to keep relatively static with the sample. The longitudinal tensile strength of flexible core-tube is also needed, because part of the penetration force loads on the flexible core-tube. In addition, the chemical and mechanical property of material should be inert and stable to prevent the pollution of sample. This paper aims to devise a new high-performance textile flexible core-tube.

\section{Characteristics of PBO}

PBO fibers was commercialized by Toyobo Co. in 1998 after about 20 years research in United States and Japan with the trade name Zylon. It belongs to the class of high performance fibers commonly known as rigid-rod polymers [5]. Table 1 summarizes properties of various fibers. PBO fibers have mainly three advantages: high tensile strength, high tensile modulus and excellent heat resistance. It has been used in space exploration. Prototype Mars exploration balloon tested in 2002 utilized PBO tendons [6].

Table. 1 The mechanical properties of high performance fibers

\begin{tabular}{cccccc}
\hline Type of fibers & $\begin{array}{c}\text { Tensile } \\
\text { Strength } \\
(\mathrm{GPa})\end{array}$ & $\begin{array}{c}\text { Tensile } \\
\text { Modulus } \\
(\mathrm{GPa})\end{array}$ & $\begin{array}{c}\text { Elongation } \\
(\%)\end{array}$ & $\begin{array}{c}\text { Density } \\
\left(\mathrm{kg} / \mathrm{m}^{3}\right)\end{array}$ & $\begin{array}{c}\text { Heat } \\
\text { Resistance } \\
\left({ }^{\circ} \mathrm{C}\right)\end{array}$ \\
\hline PBO & 5.80 & 280 & 1.9 & 1.56 & $-200 \sim 650$ \\
Kevlar & 3.30 & 179 & 2.5 & 1.44 & $-150 \sim 500$ \\
Twaron & 3.20 & 115 & 2.9 & 1.45 & $-150 \sim 450$ \\
T-300 & 3.20 & 230 & 1.6 & 1.76 & - \\
Armos & 4.20 & 130 & 3.5 & 1.43 & $-150 \sim 500^{\circ} \mathrm{C}$ \\
\hline
\end{tabular}

According to some reports, flexible core-tube developed by the former Soviet union may adopt the Armos fibers which is the most advanced material at that time. Comprehensive performance of PBO is far higher than that of Armos fibers. In the condition of the mechanism design of the existing subsurface sampler, slow heat dissipation leads to the local temperature of the bit rises sharply. Due to the extreme temperature environment, it is advisable that the flexible core-tube adopts PBO fibers.

\section{Development of Flexible Core-Tube}

High strength and modulus fibers belongs to brittle material, which is easy to get pilling or yarn break and affects the appearance, workability and strength of flexible core-tube. Warp sizing is the most effective way to improve the weaving property of precursor fibers. High performance fibers is treated by warp sizing combining yarn twisting. Appropriate parameters of the warp sizing and yarn twisting process can optimize the weaving performance, and meanwhile, guarantee the strength of yarn. Warp sizing and yarn twisting devices are shown in Fig. 2.
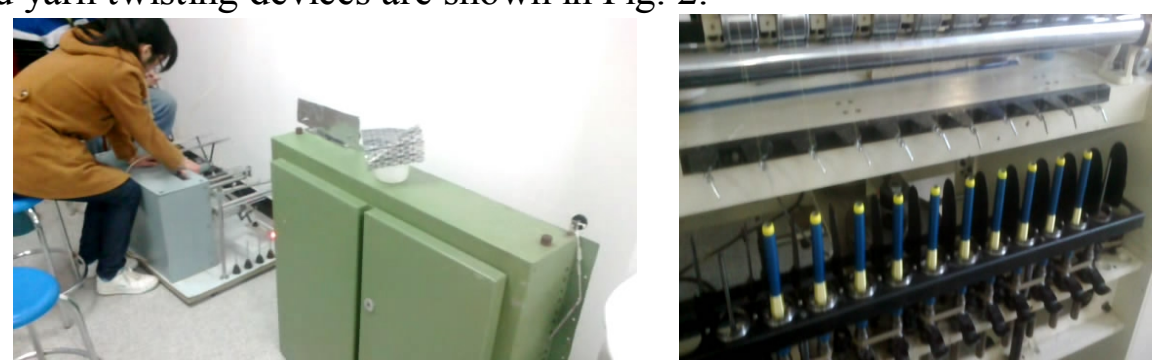

Fig. 2 Warp sizing and yarn twisting device

After precursor fiber pretreatment, the weaving scheme and process design of flexible core-tube is investigated in this paper, including gaiting, modification and debugging of weaving equipment, 
weaving technology research, warp/weft density control, the size design (thickness, size), optimization of process design and the mechanical structure design. The fabric structure parameters are designed, the characterization is tested, and combining with necessary finishing technology, the anisotropic tubular woven fabric is developed. The weaving process is shown in Fig. 3.

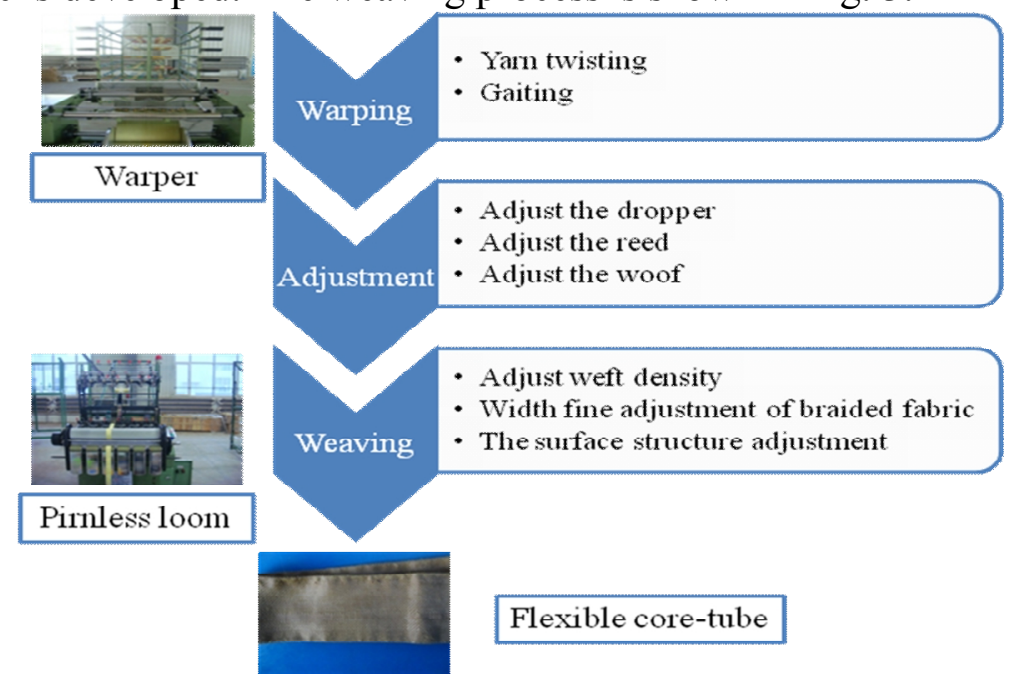

Fig. 3 The schematic of weaving process

\section{Testing Result}

The breaking strength of flexible core-bute is tested by universal testing machine at room temperature. The sample length is $200 \mathrm{~mm}$, preload is $30 \mathrm{~N}$, the loading speed is $20 \mathrm{~mm} / \mathrm{min}$, and sample width is $28.6 \mathrm{~mm}$. Due to the uneven fracture, there are measurement deviations, within $\pm 300 \mathrm{~N}$. The tensile test results of the flexible core-bute is shown in Fig. 4. The test results are shown in Table. 2.

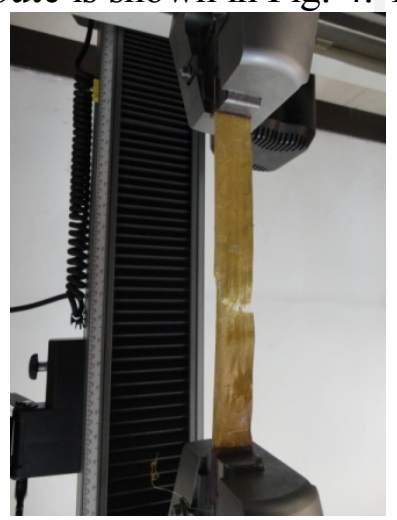

Fig. 4 The fracture of the flexible core-tube in the breaking strength test

Table. 2 The breaking strength of the flexibl core-tube

Average breaking load Minimum breaking load ultimate breaking load

$4178 \mathrm{~N} 4044 \mathrm{~N} \quad 4312 \mathrm{~N}$

The data comparison of mechanical properties under high temperature and vacuum storage condition with normal environment is shown in Table. 3 . The result shows that the mechanical property of flexible core-tube falls slightly in high temperature storage $\left(120^{\circ} \mathrm{C}\right)$ and vacuum $(0.090 \mathrm{MPa})$ condition.

Table. 3 The data comparison of mechanical property

\begin{tabular}{cc}
\hline $\begin{array}{c}\text { Average breaking load in } \\
\text { normal environment }\end{array}$ & $\begin{array}{c}\text { Average breaking load } \\
120^{\circ} \mathrm{C} 0.090 \mathrm{MPa}\end{array}$ \\
\hline $4178 \mathrm{~N}$ & $4035 \mathrm{~N}$ \\
\hline
\end{tabular}


Another group of data comparison of mechanical property under low temperature $\left(-180^{\circ} \mathrm{C}\right)$ and high vacuum $(0.090 \mathrm{MPa})$ storage condition with normal environment is shown in Table. 4 . The result shows that the mechanical property of flexible core-tube changes quite little under low temperature storage and vacuum condition.

\begin{tabular}{cc}
\multicolumn{2}{c}{ Table. 4 data Comparison of mechanical property } \\
\hline $\begin{array}{c}\text { Average breaking load } \\
\text { in normal environment }\end{array}$ & $\begin{array}{c}\text { Average breaking load } \\
-180^{\circ} \mathrm{C} 0.090 \mathrm{MPa}\end{array}$ \\
\hline $4178 \mathrm{~N}$ & $4173 \mathrm{~N}$ \\
\hline
\end{tabular}

\section{Summary}

Basing on the analysis of the history of the lunar subsurface sample return methods, a new kind of PBO fiber textile core-tube that can improve the performance of the sample system is devised. And the proceeding process of the core-tube is introduced, including gaiting, weaving equipment and technology, density control, size and structure design. The product is tested in extreme temperature and vacuum enviroment, and the results show that the mechanic properties is stable enough for the design requirement.

\section{References}

[1] Apollo 11 Mission Report. Manned Spacecraft Center, Mission Evaluation Team (Houston, Texas: NASA). November 1969. OCLC 10970862. MSC-00171. Retrieved July 102013.

[2] Information on https://curator.jsc.nasa.gov/lunar/lsc/luna24core.pdf

[3] W. Carrier, G. R. Olhoeft, W. Mendell, Lunar Sourcebook, Cambridge University Press, Cambridge, 1991, pp. 27-30.

[4] K. Zacny, Y. Bar-Cohen, Drilling in Extreme Environments, VILEYVCH, 2008, pp. 65-67.

[5] Afshari M, Sikkema D J, Lee K, et al. High Performance Fibers Based on Rigid and Flexible Polymers. Polymer Reviews. 2008

[6] Seely, L. Zimmerman, M. McLaughlin, L. The use of Zylon fibers in ULDB tendons, Advances in Space Research 2004, 33, 1736-1740. 